\title{
Market orientation: reflections on field-based, discovery-oriented research
}

\author{
Gregory S. Carpenter ${ }^{1}$ (D)
}

Received: 2 May 2017 / Accepted: 10 May 2017 / Published online: 2 June 2017

(C) Academy of Marketing Science 2017

\begin{abstract}
For years, market orientation remained an appealing concept that was, in practice, less favored than other approaches to management. A surge of research on market orientation helped clarify the concept and provide needed logical structure, creating a foundation for the further research and for adoption in practice. Among the most influential papers in that surge is Kohli and Jaworski (Journal of Marketing, 54, 1-18, 1990). In this paper, we comment on Jaworski and Kohli's essay, exploring the process for field-based, discoveryoriented research, drawing comparisons with experimental, analytical or empirical approaches. We explore how one formulates and poses questions differently, the process of choosing collaborators, differences in the data collection, analysis, and differences in crafting papers. Illustrating these differences with Kohli and Jaworksi (Journal of Marketing, 54, $1-18,1990$ ), we explore more recent advances in market orientation and propose directions for future work.
\end{abstract}

Keywords Market orientation · Organizational culture · Ethnography

\section{Introduction}

The embrace of market orientation in the practice of management has been a long time coming. More than sixty years ago, Drucker (1954) argued that the purpose of business is quite simply to "create a customer." From that perspective, he

Gregory S. Carpenter

g-carpenter@kellogg.northwestern.edu

1 Kellogg School of Management, Northwestern University, Evanston, IL 60208, USA continued, "Marketing is so basic that it cannot be considered a separate function...It is the entire business seen from the point of view of its final result, that is, from the customer's point of view...Marketing must, therefore, permeate all areas of the enterprise." As the concept became a foundation of marketing thought (e.g., Kotler and Levy 1969), firms largely chose to operate with a separate marketing function. Many firms continue to do so, but firms such as Amazon, General Electric, and Zappos are infusing the consumer perspective throughout the organization. It appears that real change is well underway.

Why has this change been so long in coming? Despite the compelling logic of the marketing concept, how a firm might actually operate with the customer perspective permeating the organization was, for many years, entirely unclear. Shapiro (1988) highlighted the challenge, describing a classicallystructured company, in which each function sees itself as market oriented and contributing to the success of the organization, despite a fundamental lack of consensus across functions. Even the language used to describe market orientation was unclear. Different terms such as the marketing concept, customer orientation and market orientation were used to describe similar if not identical concepts. In short, there was agreement on the importance of focusing on the market, but not much else. The concept of market orientation remained an elusive, distant goal that lacked definition, as if obscured by fog.

With funding from the Marketing Science Institute, research on market orientation increased dramatically (e.g., Deshpandé et al. 1989; Kohli and Jaworski 1990; Narver and Slater 1990). The findings emerging from these efforts provided much needed clarity, deeper logical structure, and the foundation for a greater consensus and future work, lifting the fog. Among the most significant of these papers is Kohli and Jaworski (1990). A paper of remarkable influence and impact, it continues to play a central role in our understanding of market orientation as a set of distinct 
behaviors associated with the flow of information within the firm.

Kohli and Jaworski (1990) employs fields-based, discoveryoriented methods. While very common in consumer behavior, such methods are less often used to explore more managerial topics. For some questions, however, field-based, discoveryoriented research is remarkably well suited. Indeed, for the right question at the right moment, field-based research can have a remarkable impact. Kohli and Jaworski (1990) is an excellent example of such research. It is a pleasure to have the opportunity to offer some reaction to their reflections on the process used to develop their 1990 paper (Jaworski and Kohli 2017) and more generally to reflect on the role of field-based, discovery-oriented research to explore more managerial topics.

\section{Lifting the fog}

Jaworski and Kohli (2017) offers a rare peak into the process of crafting of high-impact field-based, discovery-oriented research. Making enduring, important contributions is challenging, requiring a number of key decisions throughout the research process. Different approaches to research, including experiments, analytical modeling, empirical modeling and field-based work share a similar process but, in my experience, field-based requires a significantly different approach to the research process, from asking the right question to crafting the results.

\section{Asking questions}

Research begins of course with a question. Once you choose a question, of course, answers hopefully flow directly. Asking the wrong question or asking questions poorly, however, can simply lead to confusion. Many times, it would appear that scholars believe that answering questions is more challenging than asking them. But when considering questions, I am often reminded of Picasso's comments on computers. "They are useless. They only give you answers." There is no substitute for a good question. Sometimes posing questions is more difficult than findings answers. The question you pose is often critical to the success of the research.

For field-based research, this is especially so. Where experimental and empirical research often seeks to test theories and measure effects by simplifying reality to a small set of relationships that can be examined in detail, discoveryoriented work seeks to gain a more holistic understanding of a complex phenomenon, often in a context that is itself complex. If experimental and empirical methods are well suited to provide precise answers to complex questions, field-based methods are well suited to provide complex answers to precise questions. For example, how do consumers feel about Botox (Giesler 2012), gambling (Humphreys 2010), and how do wine producers understand wine consumers (Humphreys and Carpenter 2017)? Part of the challenge of field-based research, therefore, is to pose precise question that will yield the most interesting, rich, revealing answers.

Kohli and Jaworski (1990) identify this challenge, noting that "we would focus on a 'fuzzy concept' that had been identified-but was not precisely defined, understood, measured or theorized about" (Jaworski and Kohli 2017). Taking on that challenge as young, untenured faculty members is clearly risky. As Jaworski and Kohli (2017) recall, it was a high-risk, high-return project. Other teams were working on the topic, some with more senior scholars, and Kohli and Jaworski had successful research in other areas. Their choice to pursue market orientation reflects a significant degree of strategic thinking: There was considerable interest in the topic, it was important to practice, and MSI had given its endorsement through a small conference along with funding. In my view, this is the perfect combination for a passionate team. They have the rare opportunity, if not to be first, to be early movers in laying the foundation for what follows. In some sense, it is an ideal opportunity to be market driving (e.g., Jaworski et al. 2000).

For those sorts of challenges, field-based discovery-oriented research can be very effective. Although it produces massively complex data with little obvious structure, field-based research provides the opportunity to understand the phenomenon holistically and, with that larger perspective, identify core concepts. Through their field work, Kohli and Jaworski (1990) developed the construct of market orientation focusing on the flow of market intelligence, describing market orientation as consisting of the generation of market intelligence, the dissemination of that intelligence across the firm, and the response of the firm to market intelligence. The generation of market intelligence includes identifying customers, and understanding customers' current and future needs. Dissemination of market intelligence includes communicating and sharing information about the market across functions to help develop coordinated responses to the market. Responding to market intelligence includes selecting target markets, offering product and services, and delivering the value customers expect. These rich insights illustrate the power of asking the right question.

\section{Collaborators}

For all research, the choice of collaborators is important, but for field-based research, the choice of collaborators is especially important. Field-based, discovery-oriented research yields large amounts of data. Processing this data is conceptually something like factor analysis. Field-based data are, however, unstructured and saturated with ambiguity. Like factor analysis, multiple solutions exist. In my experience, two heads can be much better than one when it comes to finding the best solution. Each collaborator brings a different 
perspective, different lens, and differing abilities to bring structure and abstraction to the analysis. Too many perspectives, however, can frustrate finding a solution. Ultimately, the analysis needs to converge to a solution that ideally yields maximum insight. In some fields such as medical sciences research teams can be quite large, but for field-based work the optimal number of collaborators is more modest, making the choice of collaborators even more important.

So how do you choose? Jaworski and Kohli (2017) describe their process as facilitated by common background, similar commitment, similar values, alignment on goals, and the desire to enjoy the process. In my experience, these are critical ingredients of successful collaborations and, especially so, in the case of qualitative research. To this, however, I would add one dimension, which may be idiosyncratic. I have always found collaborating with individuals with dissimilar backgrounds to be very helpful. One goal of qualitative research is to see the familiar as strange and the strange as familiar. If everyone on the team sees the world through the same lens, important insights may be missed. At the same time, individuals who are too dissimilar may fail to see common ground, so there seems to be an optimal level of dissimilarity, which may vary across teams and individuals.

In addition to developing the construct of market orientation more fully, they proposed a series of research propositions, including identifying antecedents and consequences of market orientation. All appear to be the result of an extraordinarily effective collaboration, developing a coherent theoretical perspective from a highly unstructured data set. The propositions identify antecedents, including the role of senior management, interdepartmental dynamics, and organizational systems, and explore their role on market orientation. They similarly develop a set of propositions about the consequences of market orientation, including exploring the relationship between market orientation and customer responses, business performance and employee responses. These propositions bring further clarity to the market orientation construct. They give us a window into the authors' thinking, reflecting interviews, analysis and discussion. As such, they provide a powerful basis for future work.

\section{Doing the research}

Doing field-based, discovery-oriented research is a different experience compared to experimental, analytical or empirical modeling. One important difference is data collection. Analytical work requires little formal data collection, experimental work depends on the ability to design experiments, and empirical work requires securing data sets. Collecting useful field-based data depends on interview skills and powers of observation. We all wear a mask (Goffman 1956). Seeing behind the mask requires making the person you are interviewing feel comfortable to share something meaningful, even something personal. Schein (2013) describes this as humble inquiry, "the art of drawing someone out, of asking questions to which you do not know the answer, of building a relationship based on curiosity and interest in the other person." It requires having a sense when your subject is lying or deflecting. Effective inquiry depends on the researcher's ability to notice small details that reveal something more consequential than might appear at first glance. In some sense, it requires skills one might associate with a detective or therapist.

In experimental or empirical work data analysis follows data collection, but in field-based research, the data collection and data analysis begin simultaneously. What you explore depends on what you hear, see, and sense. Life is a drama, complete with actors and a stage. The goal is to develop a deep understanding of the question you are exploring, including what is said, what is unsaid, what is revealed in the conscious and unconscious behavior of those who participate in your research, and what is reflected in the physical environment you observe. Your goal is to understand the performance, real as it is. From this understand, theory is generated, relating concepts to one another. Sampling continues, adding more data on theoretical grounds. The researcher makes constant use of comparison, identifies patterns, and processes, ultimately producing hypotheses (Corbin and Strauss 1990). A very human experience, this process is full of surprises.

Jaworski and Kohli (2017) describe the start of their journey in familiar terms. "We asked interviewees what the term [market orientation] meant to them. This is not to say that we had no idea of what the concept meant; we did have a fuzzy idea...We suspended our pre-conceptions about the concept as much as we could, and listened to what the interviewees were saying." They describe pushing interviewees to "answer sequences of "why' questions until it eventually led to an interesting idea." They asked "flipped question" such as "what does a business that is not market oriented do?" As one might suspect, 15 to 20 interviews led to most of the ideas in the 1990 paper-some interviews produced surprises. Being open to understanding those surprises is critical. It is part of the theory development process. Listening, really hearing, is challenging but critical. What you hear can defy logic, seem odd, even irrational and thus easy to dismiss. But you have to understand the full meaning, not just the literal meaning. Through listening, reflecting and analysis, Kohli and Jaworski describe developing ideas, sometimes slowly, rejecting some, however logical, and developing a coherent understanding.

\section{Crafting papers}

Although writing a field-based paper is very similar to writing paper using other research methods, presenting field-based, discovery-oriented results presents unique challenges. In presenting an analytical model, empirical analysis, or 
experimental results, the author is obliged to meet norms and certain rigorous, logical standards. In reporting qualitative work, however, I am often reminded of Mark Twain's famous quotation: "The only difference between reality and fiction is that fiction needs to be credible." Findings from field-based research can defy logic and certainly challenge credibility.

Presenting findings, including the logical inconsistencies and contradictions, can be a real challenge but these "flaws" are essential to the analysis. Irrationality, contradiction, and unexpected behavior makes life interesting. Much of the richness comes from the context and the specific words used by those interviewed. Often the only way to convey the full meaning of the analysis is through text, making a paper too long. At the same time, too much detail can be overwhelming, but stripping away the detail or the context can produce a weak mix of anecdotes and conjecture. Without the richness of the context, the illogical seems simply incredible. Effective presentation requires finding a balance between richness and brevity, complexity and clarity. It can be a tough balance to achieve.

Holbrook (1986) offers some marvelous advice on finding that balance. His thoughts are offered for papers of all stripes but I find for qualitative work, he offers a few gems: (1) Do not hesitate to make your paper interesting. Field-based research is fundamentally human, with all the richness, drama, and surprises human experience offers. In the spirit of science, some scholars strip their papers of drama, emotion, and richness, focusing instead on the analysis and implications. Life is interesting. Including the richness of life can make papers interesting too. (2) Remember, brevity is the soul of wit. Include as much detail as you need but nothing more. (3) Adjust the length of your paper to the magnitude of its contribution. Every scholar seems taken with his or her work, understandably so. But not everyone is, and some papers have less to say, some more to say. Understand your audience, focus your analysis, and adjust accordingly. Kohli and Jaworski (1990) exemplify many of Holbrook's principles.

\section{After the fog lifts}

Research on market orientation has continued at an astonishing pace. Over 1000 articles on market orientation have been published since 1990 (Jaworski and Kohli 2017), exploring the financial rewards associated with market orientation, how firms become more market oriented, and the application of market orientation to specific situations, such as creative industries.

\section{Impact on performance}

Of all these advances, among the most influential have been the studies exploring the impact of market orientation on firm performance (Cano et al. 2004; Deshpandé and Farley 1998; Homburg and Pflesser 2000; Kumar et al. 2011, and Narver and Slater 1990). Empirical studies report a positive relationship between market orientation and firm performance (e.g., Cano et al. 2004; Deshpandé and Farley 1998; Homburg and Pflesser 2000; Narver and Slater 1990). These findings support the power of the customer and the importance of a market orientation to achieving superior performance.

Other studies, however, have identified important moderating effects and boundary conditions (e.g., Gatignon and Xuereb 1997; Kirca et al. 2005; Noble et al. 2002; Voss and Voss 2000). For example, Gatignon and Xuereb (1997) find market growth and demand uncertainty to be important moderators. Voss and Voss (2000) even find a negative relationship between market orientation and subscriber ticket sales for a theatre. Finally, the question of whether market orientation can produce sustainable superior performance remains open. Conceptually, it seems plausible; yet the evidence suggests that superior performance may not withstand competitive imitation (Kumar et al. 2011).

\section{Organizational change}

The rewards associated with market orientation have led some academics and practitioners to question, how do firms change to become more market oriented? This is a question my colleagues and I explored (Carpenter et al. 2014; Gebhardt et al. 2006). The concept of market orientation was reasonably well defined when we began the work, and research in organizational behavior offered a range of models to explain organizational change (e.g., Zald and Berger 1978). Different models, however, offered conflicting and incompatible explanations. The clarity we had hoped for did not apparently exist. Using a field-based approach, we sought to understand the process of change. To do so, we examined seven companies seeking to be more market oriented. Some of these firms succeeded, most failed. We compared the successful firms with the ones that failed and we discovered all firms took many of the same decisions, which left a puzzle. What separates success and failure, if not choices?

Further analysis revealed that the sequence of decisions was critical. Successful firms engaged in a four-stage process, starting with recognizing the limits of their current culture and organization. Next these firms immersed the organization in the customers' world, developing a shared view of the customer across all function and all levels in the organization. Third, after the firm has developed a shared sense of the market, a deep understanding of buyers, they began to make 
meaningful organizational changes, embracing marketoriented values in the process. Finally, these firms evolved, changing as their customers did over time. Although all the firms we studied had been successful before struggling, after reinvention, some firms enjoyed surprising levels of success, eclipsing their earlier successes in some cases (Carpenter et al. 2014).

\section{Culture}

As part of our investigation of organization change, we discovered that firms successfully making the transition to market orientation embrace six values. These firms operated in very different industries, with different competitive situations, and had very different histories. Even so, they shared six fundamental assumptions. First, firms recognize that they exist at the mercy of the market. The market is their the raison d'être. In the past some felt that they existed because of technology or some extraordinary manufacturing process, or even because of a God-given right, incredible as that might sound. Second, firms embraced empathy, the ability to see the world through the eyes of others, understanding what they think and feel. Being empathetic is very challenging. It requires embracing the irrational, which can be very tough for some disciplined organizations. Third, firms believe deeply in respect and collaboration. With regard to customers and other member of the firm, they demonstrate an admiration for their colleagues and customers and a willingness to work together. Finally, these firms display a remarkable sense of trust and openness. Trust is essentially a belief in the fairness, competence and honesty of your colleagues and customers, something that is in short supply in many organizations. Openness is the appetite for new approaches to being successful, which depends on trust.

Although Kohli and Jaworski (1990) focused on behavior within, our findings on culture suggested a connection. Schein (2010) describes organizational culture on three levels. Most visibly are artifacts, including the structure of the organization, stories, rituals, and organizational processes, such as the flow of information. Artifacts reflect two deeper layers of culture (1) values and norms, which are expectations about behavior shared by the group, and (2) the firm's beliefs and assumptions. Deeply held and seldom questioned, these beliefs and assumptions are the "truths" that shape norms, values, and ultimately behavior (e.g., Desphandé and Farley 1998; Gebhardt et al. 2006; Narver and Slater 1990). This cultural perspective is often described at odds with the behavior perspective on market orientation. But our research suggests that the debate is a bit like arguing about the nature of an iceberg, depending on whether you are observing it from above or below the surface. It may appear very different but in the end it's the same chunk of ice.

\section{Looking ahead}

As important as these advances are, and as voluminous as the research is, there is more to explore.

\section{A broader lens}

Research on market orientation has explored the organizational behaviors (e.g., Kohli and Jaworski 1990), the cultural value giving rise to those behaviors (e.g., Narver and Slater 1990), and the impact of a market orientation on firm performance (e.g., Homburg and Pflesser 2000). Scholars have employed field-based methods, survey research, causal modeling and ethnography. Despite a remarkable breadth of approaches and research methods, the focus of research on market orientation has been the firm itself. Customers have been excluded. One would expect that more market-oriented firms would have a deeper understanding of their customers and that an examination of customers would show a strong correspondence between a firm's understanding of customers and customers actual thinking and behavior. But existing studies offer no evidence. Research on consumer satisfaction suggests that more satisfied customers produce superior financial performance (e.g., Fornell et al. 2006), but whether market orientation leads to greater customer satisfaction remains an open question. More generally, existing research on market orientation is ironically moot on the question of whether firms described as market oriented are indeed market oriented from the consumer perspective.

Expanding the focus of market orientation beyond the firm, raises a large number of possibilities. Firms operate in a value chain but more broadly firms operate in a social system (e.g., Giesler 2012; Humphreys 2010; Humphreys and Carpenter 2017; Vargo 2011). The implicit assumption of the concept of market orientation is that the consumer is among the most, if not the most, important influence on the firm in that system. In some industries, however, other actors play a central role in firm success or failure. For example, in sports betting, financial stock markets, movies, wine, and restaurants, experts and critics play a critical role (e.g., Giesler 2012; Hadj Ali et al. 2008; Holt 2004; Humphreys 2010; Humphreys and Carpenter 2017; Vargo 2011). Indeed, critics can exert remarkable influence, shaping opinion and driving sales (Humphreys and Carpenter 2017). Adopting a broader lens to view firms as operating in larger social systems, and specifically including the consumer perspective, would seem to be potentially fruitful avenue for future research. 


\section{Market driven v. Market driving}

One very intriguing question is, how do firms embrace market orientation? Two relatively distinct approaches have been identified. Firms operate in a value chain of suppliers and customers, ultimately reaching consumers. The available technology creates the cost structure and customers create the demand structure. Assuming the number of players within the industry are fixed and the behavior of actors in the system remains consistent, firms seek to satisfy customers. Taking the demand and supply as fixed factors, firms seek to discover and meet consumer tastes. These firms are market driven (Jaworski et al. 2000).

Firms operating in the value chain, however, may assume that the structure of the market and the behavior of actors within that market are endogenous. For example, a firm may launch a disruptive technology, reshaping both the cost structure, demand structure and the number of players in an industry. Rather than simple seeking to discover consumer tastes, these firms seek to shape consumer behavior, along with the behavior of others in the industry. These firms are said to be market driving (Carpenter et al. 1997; Jaworski et al. 2000; Kumar et al. 2000).

This intriguing distinction has drawn relatively little attention from scholars. As Jaworski and Kohli (2017) note, "The idea of shaping, molding and managing the evolution of markets has been around for some time, but has not taken off in terms of systematic inquiry. This is very surprising since our observation is that a firm that sets the rules in an industry often leads the industry." Research on pioneering advantage demonstrates that firms that set the rules often earn persistently high market shares (e.g., Carpenter and Nakamoto 1989; Urban et al. 1986), raising a number of intriguing questions. What are the relative rewards associated with the marketdriven approach versus the market-driving approach? When does each produce superior results?

More fundamentally, one may ask, what is the precise nature of the market-driven approach. Often associated with disruptive innovation, it may be possible to drive a market systematically through other means, but the precise nature of those means is unclear. Humphreys and Carpenter (2017) suggest that status may be a powerful means to drive the U. S. wine market, shaping consumer preferences and exerting a powerful influence on the nature of competition. Are the gains from market-driving behavior sustainable? Research on pioneering advantage suggests a fundamental asymmetry between pioneers and later entrants (e.g., Carpenter and Nakamoto 1989; Urban et al. 1986). This asymmetry helps sustain a pioneer's high market share in the face of intense competition. Does a similar asymmetry exist in the case of market-driving behavior? This question and others would be useful to explore.

\section{Organizational logics}

In organizational behavior research, a recent area of great interest may be useful to advance marketorientation research. Research on institutional logics rests on the assumption that at a societal level, a number of influential institutions operate. These institutions include the market, the corporation, the state, democracy, nuclear family, and community. Each is guided by a distinct logic (Thornton et al. 2012). These logics are socially constructed, reflecting fundamental beliefs and assumptions about the organization, its path to success and the meaning of its activities. Organizations embrace combinations of logics from social institutions to develop their own logics. Some firms may embrace logics, for example, associated with the market as well as the corporation. The blend of logics can be seen as a sort of organizational culture. If one considers a market orientation as one particular organizational logic, this work would appear to offer a new and very useful perspective to enrich market orientation research, especially in broadening the focus of market orientation research beyond the singular focus on the firm.

\section{Conclusion}

At the right moment, with the right question, fieldbased, discovery-oriented) research can produce remarkably powerful insights. Gaining these insights requires navigating a challenging process. Rather than focusing on precise answers to complex questions, field-based work focuses on precise questions that yield complex answers. The data collection process and a data analysis process begin simultaneously, and the investigator must be part scientist, part detective, part humble inquirer, recognizing deception and deflection to unmask subjects. Processing that data is best done through collaborations that balance diversity of perspective yet seek common understanding. Sharing the findings of such efforts with others, especially those who do not engage in field-based research, requires presenting the richness of the analysis, the logic of the system, and the human drama, emotion and irrationality that pervade behavior. As Kohli and Jaworski (1990) illustrates, field-based discovery-oriented done well can, through this somewhat unusual process, bring greater clarity, deeper logic, and create a solid foundation with remarkable impact and endurance. 


\section{References}

Cano, C. R., Carrillat, F. A., \& Jaramillo, F. (2004). A meta-analysis of the relationship between market orientation and business performance: Evidence from five continents. International Journal of Research in Marketing, 21(2), 179-200.

Carpenter, G. S., \& Nakamoto, K. (1989). Consumer preference formation and pioneering advantage. Journal of Marketing Research, 26, 285-298.

Carpenter, G. S., Glazer, R., \& Nakamoto, K. (1997). Readings on market-driving strategies: Towards a new theory of competitive advantage. Reading: Addison Wesley Longman.

Carpenter, G. S., Gebhardt, G. F., \& Sherry Jr., J. F. (2014). Resurgence: The four stages of market-focused reinvention. New York: PalgraveMacmillan.

Corbin, J., \& Strauss, A. (1990). Grounded theory research: Procedures, canons and evaluative criteria. Qualitative Sociology, 13, 3-21.

Deshpandé, R., \& Farley, J. U. (1998). The market orientation construct: Correlations, culture, and comprehensiveness. Journal of MarketFocused Management, 2, 237-239.

Desphandé, R., Farley, J. U., Webster, F. E., \& Jr. (1989). Organizational culture and marketing: Defining the research agenda. Journal of Marketing, 53, 3-15.

Drucker, P. F. (1954). The practice of management. New York: Harper \& Row.

Fornell, C., Mithas, S., Morgeson III, F. V., \& Krishnan, M. S. (2006). Customer satisfaction and stock prices: High returns, low risk. Journal of Marketing, 70, 3-14.

Gatignon, H., \& Xuereb, J.-M. (1997). Strategic orientation of the firm and new product performance. Journal of Marketing Research, 34, $77-90$.

Gebhardt, G. F., Carpenter, G. S., \& Sherry Jr., J. F. (2006). Creating a market orientation: A Longitudinal, Multifirm, grounded analysis of cultural transformation. Journal of Marketing, 70, 37-55.

Giesler, M. (2012). How Doppelgänger brand images influence the market creation process: Longitudinal insights from the rise of Botox cosmetic. Journal of Marketing, 76, 55-68.

Goffman, Erving. (1956). The presentation of self in everyday life. Edinburgh: University of Edinburgh.

Hadj Ali, H., Lecoq, S., \& Visser, M. (2008). The impact of gurus: Parker grades and En Primeur wine prices. Economic Journal, 118, 158-173.

Holbrook, M. B. (1986). A note on sadomasochism in the Review process: I hate when that happens. Journal of Marketing, 50, 104-108.

Holt, D. B. (2004). How brands become icons: The principles of cultural branding. Boston: Harvard Business Press.

Homburg, C., \& Pflesser, C. (2000). A multiple-layer model of marketoriented organizational culture: Measurement issues and performance outcomes. Journal of Marketing Research, 37, 449-462.

Humphreys, A. (2010). Megamarketing: The creation of markets as a social process. Journal of Marketing, 74, 1-19.
Humphreys A, Carpenter GS. (2017) Red White \& cru: Market orientation in the U. S. Wine Industry. Working paper, Northwestern University.

Jaworski, B. J., \& Kohli, A. K. (2017). Conducting field-based, discovery-oriented research: Lessons from our market-orientation research experience. AMS Review. doi:10.1007/s13162-017-0088-5.

Jaworski, B. J., Kohli, A. K., \& Sahay, A. (2000). Market-Driven versus Driving Markets. Journal of the Academy of Marketing Science, 28, 45-54.

Kirca, A. H., Jayachandran, S., \& Bearden, W. O. (2005). Markety orientation: A meta-analytic Review and assessment of its antecedents and impact on performance. Journal of Marketing, 69, 24-41.

Kohli, A. K., \& Jaworski, B. J. (1990). Market orientation: The construct, research propositions, and managerial implications. Journal of Marketing, 54, 1-18.

Kotler, P., \& Levy, S. J. (1969). Broadening the Conept of marketing. Journal of Marketing, 33, 10-15.

Kumar, N., Scheer, L., \& Kotler, P. (2000). "From Market Driven to Market Driving," European Management Journal, 18, 129-142

Kumar, V., Jones, E., Venkatesan, R., \& Leone, R. P. (2011). Is market orientation a source of sustainable competitive advantage or simply the cost of competing? Journal of Marketing, 75, 16-30.

Narver, J. C., \& Slater, S. F. (1990). The effect of a market orientation on business profitability. Journal of Marketing, 54, 20-35.

Noble, C. H., Sinha, R. K., \& Kumar, A. (2002). Market orientation and alternative strategic orientations: A Longitudinal assessment of performance implications. Journal of Marketing, 66, 25-39.

Schein, E. H. (2010). Organizational culture and leadership. San Francisco: Jossey-Bass.

Schein, E. H. (2013). Humble inquiry: The gentle art of asking instead of telling. San Francisco: Berrett-Koehler Publishers.

Shapiro, B. S. (1988). What the Hell is 'Market Oriented. Harvard Business Review, 66, 119-125.

Thornton, P. H., Ocasio, W., \& Lounsbury, M. (2012). The institutional logics perspective: A new approach to culture, structure and process. Oxford: Oxford University Press.

Urban, G. L., Carter, T., Gaskin, S., \& Mucha, Z. (1986). Market share rewards to pioneering brands: An empirical analysis and strategic implications. Management Science, 32, 645-659.

Vargo, S. L. (2011). Market systems, stakeholders and value propositions: Toward a service-dominant logic-based theory of the market. European Journal of Marketing, 45, 217-222.

Voss, G. B., \& Voss, Z. G. (2000). Strategic orientation and firm performance in an artistic environment. Journal of Marketing, $64,67-83$.

Zald, M. N., \& Berger, M. A. (1978). Social movements in organizations: Coup D'Etat, insurgency, and mass movement. American Journal of Sociology, 83, 823-861. 